\title{
Development and optimization of carvedilol orodispersible tablets: enhancement of pharmacokinetic parameters in rabbits
}

This article was published in the following Dove Press journal:

Drug Design, Development and Therapy

5 March 2015

Number of times this article has been viewed

\author{
Yazeed HM Aljimaee' \\ Abdel-Rahim M El-Helw' \\ Osama AA Ahmed 1,2 \\ Khalid M El-Say',3 \\ 'Department of Pharmaceutics \\ and Industrial Pharmacy, Faculty \\ of Pharmacy, King Abdulaziz \\ University, Jeddah, Saudi Arabia; \\ ${ }^{2}$ Department of Pharmaceutics \\ and Industrial Pharmacy, Faculty \\ of Pharmacy, Minia University, Minia, \\ ${ }^{3}$ Department of Pharmaceutics and \\ Pharmaceutical Technology, Faculty \\ of Pharmacy, Al-Azhar University, \\ Cairo, Egypt
}

Background: Carvedilol (CVD) is used for the treatment of essential hypertension, heart failure, and systolic dysfunction after myocardial infarction. Due to its lower aqueous solubility and extensive first-pass metabolism, the absolute bioavailability of CVD does not exceed $30 \%$. To overcome these drawbacks, the objective of this work was to improve the solubility and onset of action of CVD through complexation with hydroxypropyl- $\beta$-cyclodextrin and formulation of the prepared complex as orodispersible tablets (ODTs).

Methods: Compatibility among CVD and all tablet excipients using differential scanning calorimetry and Fourier transform infrared spectroscopy, complexation of CVD with different polymers, and determination of the solubility of CVD in the prepared complexes were first determined. A Box-Behnken design (BBD) was used to study the effect of tablet formulation variables on the characteristics of the prepared tablets and to optimize preparation conditions. According to BBD design, 15 formulations of CVD-ODTs were prepared by direct compression and then evaluated for their quality attributes. The relative pharmacokinetic parameters of the optimized CVD-ODTs were compared with those of the marketed CVD tablet. A single dose, equivalent to $2.5 \mathrm{mg} / \mathrm{kg} \mathrm{CVD}$, was administered orally to New Zealand white rabbits using a double-blind, randomized, crossover design.

Results: The solubility of CVD was improved from 7.32 to $22.92 \mathrm{mg} / \mathrm{mL}$ after complexation with hydroxypropyl- $\beta$-cyclodextrin at a molar ratio of 1:2 (CVD to cyclodextrin). The formulated CVD-ODTs showed satisfactory results concerning tablet hardness $\left(5.35 \mathrm{~kg} / \mathrm{cm}^{2}\right)$, disintegration time (18 seconds), and maximum amount of CVD released $(99.72 \%)$. The pharmacokinetic data for the optimized CVD-ODT showed a significant $(P<0.05)$ increase in maximum plasma concentration from 363.667 to $496.4 \mathrm{ng} / \mathrm{mL}$, and a shortening of the time taken to reach maximum plasma concentration to 2 hours in comparison with the marketed tablet.

Conclusion: The optimized CVD-ODTs showed improved oral absorption of CVD and a subsequent acceleration of clinical effect, which is favored for hypertensive and cardiac patients. Keywords: bioavailability, Box-Behnken design, hydroxypropyl- $\beta$-cyclodextrin, oral absorption

\section{Introduction}

Carvedilol(CVD) ( \pm )-[3-(9H-carbazol-4-yloxy)-2-hydroxypropyl][2-(2-ethoxyphenoxy) ethyl] amine is an $\alpha_{1}, \beta_{1}$, and $\beta_{2}$-adrenergic receptor blocker. CVD is used for the treatment of essential hypertension and other cardiovascular disorders such as heart failure and myocardial infarction. ${ }^{1,2} \mathrm{CVD}$ is a basic drug that exhibits $\mathrm{pH}$-dependent solubility with a $\mathrm{pKa}$ value of 7.8. At acidic $\mathrm{pH}, \mathrm{CVD}$ shows slight improvement of aqueous solubility as a result of drug ionization, but shows extremely low solubility at alkaline $\mathrm{pH}$ levels, which may hinder drug absorption in the small intestine and colon. ${ }^{3}$
Correspondence: Khalid M El-Say Pharmaceutical Technology Research Laboratory, Department of Pharmaceutics \& Industrial Pharmacy Faculty of Pharmacy, King Abdulaziz University, PO Box 80260, Jeddah 21589, Saudi Arabia

Tel +966 I264 0000 (Ext. 20073)

Fax +96626951696

Email kelsayl@kau.edu.sa 
CVD undergoes significant first-pass metabolism and also has poor aqueous solubility, resulting in low (about 30\%) bioavailability. ${ }^{4,5}$

Solubility problems are a major barrier for drug formulators, since about $40 \%$ of the marketed drugs are classified as practically insoluble. ${ }^{6}$ Several attempts have been made to improve the dissolution rate of CVD utilizing self-emulsifying and nanoemulsifying delivery systems, formation of inclusion complexes with cyclodextrins (CDs), and formulation as buccal sprays that have successfully improved the bioavailability of CVD. ${ }^{7-10}$ In addition, improved CVD bioavailability has been observed following absorption from the buccal mucosa and the lower portions of the gastrointestinal tract. ${ }^{11,12}$

The oral route is the most preferred route for drug administration. ${ }^{13}$ To avoid swallowing problems, orodispersible tablets (ODTs) were designed to disintegrate rapidly in saliva. This improves drug dissolution as well as the onset of clinical effect and pregastric absorption of drugs. Molecular dispersions, as solid dispersions, improve drug solubility through molecular dispersions of drug particles after carrier dissolution and improved drug wettability. ${ }^{14}$ This technique enhances the solubility of poorly soluble drugs, such as CVD, to meet the compendial requirements of ODTs.

Accordingly, the aim of this work focuses on improvement of the solubility of CVD and enhancement of its onset of effect through formulation of CVD as ODTs that disintegrate rapidly on contact with saliva. Response surface methodology was utilized to help in production of an optimized formulation of ODTs that have acceptable hardness, a shorter disintegration time, and maximum amount of CVD release. Box-Behnken design (BBD) was implemented to understand the formulation parameters that affect the preparation and characteristics of ODTs. Pharmacokinetic parameters of the optimized CVD-ODTs were compared with those of the presently marketed CVD tablets in rabbits. Successful achievement of this formulation could improve patient convenience and compliance because of its ease of administration, particularly for patients for whom swallowing of a conventional solid oral dosage form is a challenge.

\section{Materials and methods}

\section{Materials}

CVD was supplied by Riyadh Pharma, Riyadh (Saudi Arabia) and $\alpha, \beta, \gamma$, and hydroxylpropyl- $\beta$ (HP- $\beta$ ) CDs were provided by Nihon Shokuhin Kako Co Ltd (Tokyo, Japan). Polyvinyl pyrrolidone (PVP) with average molecular weights of 44,000 (PVP K30), and 360,000 (PVP K90) were purchased from Fluka AG, Buchs SG, (Switzerland). Camphor was sourced from Koch-Light Laboratories Ltd (Coinbrook, England), microcrystalline cellulose (Avicel PH 101) from Fluka (Hach Lange, Ireland), sodium starch glycolate (Explotab) from JRS Pharma (Patterson, NY, USA), mannitol and magnesium stearate from Winlab (Market Harborough, UK), talc from Holyland (Saudi Arabia), and methanol from Sigma-Aldrich (Seelze, Germany). All other chemicals and solvents were of analytical grade.

\section{Preparation of CVD binary systems}

Solid binary systems of CVD with different polymers, ie, PVP K30, PVP K90, and $\alpha, \beta$, $\gamma$ and HP- $\beta-C D$ in different ratios were prepared by the kneading method. ${ }^{15,16}$ The calculated amounts of CVD and the hydrophilic polymers used were triturated in a mortar with a small volume of a solvent blend of water:methanol $(1: 1 \mathrm{v} / \mathrm{v})$ to form a homogeneous slurry. The thick slurry formed was kneaded for 45 minutes then dried at $55^{\circ} \mathrm{C}$ in a hot air oven. The dried powder was then passed through mesh No 200.

\section{Saturation solubility studies}

The effects of the solid dispersion and inclusion complex on the solubility of CVD were evaluated according to the Higuchi and Connors method. ${ }^{17}$ Briefly, excess amounts of pure CVD and CVD complexes were mixed with $10 \mathrm{~mL}$ of distilled water in screw-capped vials kept in a thermostatically controlled shaking water bath at $25^{\circ} \mathrm{C} \pm 0.5^{\circ} \mathrm{C}$ for 48 hours. Samples were analyzed every day until equilibrium was reached. Thereafter, aliquots were withdrawn, filtered through a $0.22 \mu \mathrm{m}$ filter, and assayed spectrophotometrically for drug content at $242.5 \mathrm{~nm}$.

\section{Differential scanning calorimetry}

Differential scanning calorimetry was used for thermal analysis of CVD alone and CVD mixed with ODTs excipients ( $2 \mathrm{mg}$ samples) using aluminum crucibles in a dynamic nitrogen atmosphere (flow rate $50 \mathrm{~mL}$ per minute) and at a heating rate of $10^{\circ} \mathrm{C}$ per minute in the temperature range of $25^{\circ} \mathrm{C}-400^{\circ} \mathrm{C}$.

\section{Fourier transform infrared spectroscopy}

Fourier transform infrared spectra were recorded on a Jasco FT IR-6100 spectrometer using $\mathrm{KBr}$ discs with a $2 \mathrm{~cm}^{-1}$ resolution in the range of $4,000-400 \mathrm{~cm}^{-1}$.

\section{Application of BBD experimental design}

To study the effects of different variables on the characteristics of the produced ODTs and optimize the process to obtain them with a minimum disintegration time, acceptable 
Table I Independent and dependent variables in Box-Behnken design

\begin{tabular}{llll}
\hline Independent variables & \multicolumn{2}{l}{ Levels } \\
\cline { 2 - 4 } & $-\mathbf{I}$ & $\mathbf{0}$ & $+\mathbf{I}$ \\
\hline Explotab percentage & 4 & 5 & 6 \\
Camphor percentage & 2 & 3 & 4 \\
Avicel percentage & 15 & 20 & 25 \\
Dependent variables & \multicolumn{2}{l}{ Constraints } & \\
& Low & High & Goal \\
Hardness $\left(\mathrm{kg} / \mathrm{cm}^{2}\right)$ & 4.41 & 5.35 & Maximize \\
Disintegration time (seconds) & 18 & 87 & Minimize \\
Release at one hour (\%) & 89.22 & 99.72 & Maximize \\
\hline
\end{tabular}

strength, and rapid release pattern, a three-level, three-factor BBD was used. These variables are the percentage of superdisintegrant, sodium starch glycolate (Explotab) $\mathrm{X}_{1}$, subliming agent (camphor) $\mathrm{X}_{2}$, and the used binder (Avicel) $\mathrm{X}_{3}$. The responses selected for evaluation and optimization were hardness of the prepared tablets $\left(\mathrm{Y}_{1}\right)$, disintegration time $\left(\mathrm{Y}_{2}\right)$, and cumulative amount of drug released after one hour $\left(\mathrm{Y}_{3}\right)$. The design was performed with Statgraphics Plus ${ }^{\circledR}$ For Windows (Manugistics Inc, Rockville, MD, USA). The design suggests 15 experimental runs. Table 1 summarizes the independent variables with their intervals and the dependent variables selected to perform the BBD.

\section{Preparation of CVD-ODTs}

Formulations of CVD-ODTs were prepared by the direct compression method. Fifteen tablet formulations of $250 \mathrm{mg}$ total weight and containing drug complex equivalent to $12.5 \mathrm{mg}$ CVD with different ratios of tablet excipients were prepared according to the formulations given in Table 2 . The obtained blend was directly compressed by $7 \mathrm{~mm}$ flat round punches using a tablet machine (Erweka, GmbH, Heusenstamm, Germany).

\section{Evaluation of the prepared ODTs}

The prepared CVD-ODTs were evaluated for visual appearance, uniformity of content and weight, thickness, hardness, friability, and in vitro disintegration according to US Pharmacopeia tests for tablets. ${ }^{18}$

\section{In vitro dissolution test}

Drug release from the CVD-ODTs was determined by USP dissolution apparatus II (paddle) using a DT 700 LH device (Erweka). The dissolution medium was $900 \mathrm{~mL}$ of distilled water at $37^{\circ} \mathrm{C} \pm 0.5^{\circ} \mathrm{C}$ containing $0.05 \% \mathrm{w} / \mathrm{v}$ sodium lauryl sulfate with stirring at $50 \mathrm{rpm}$. Samples of $5 \mathrm{~mL}$ were withdrawn at $5,10,15,20,30,45$, and 60 minutes and replaced with fresh dissolution medium at $37^{\circ} \mathrm{C} \pm 0.5^{\circ} \mathrm{C}$. The withdrawn samples were filtered and analyzed after appropriate dilution using an ultraviolet spectrophotometer at $242.5 \mathrm{~nm}$.

\section{Kinetic treatment of release data}

The release data for CVD were fitted to zero-order, firstorder, Higuchi, and Korsmeyer-Peppas kinetic models. ${ }^{19-23}$ The best fitted model was selected to describe the mechanism of drug release from the prepared ODTs.

\section{In vivo and pharmacokinetic parameters}

\section{Subject population}

Male New Zealand white rabbits $(2-2.5 \mathrm{~kg})$ were administered a single oral dose of CVD $(2.5 \mathrm{mg} / \mathrm{kg})$. Animal use was approved by the unit of biomedical ethics, KAU which ensures that the care and use of animals conforms to the European Union Directive 2010/63/EU concerning the protection of animals used for scientific purposes. ${ }^{24}$ The rabbits were fasted for at least 24 hours prior to the experiment and were allowed free access to water. Animals were divided into

Table 2 Composition of the orodispersible tablet formulations of carvedilol

\begin{tabular}{|c|c|c|c|c|c|}
\hline Formulation & Drug complex (mg) & Explotab (mg) & Camphor (mg) & Avicel (mg) & Mannitol (mg) \\
\hline $\mathrm{FI}$ & 100 & 10 & 5 & 50 & 80 \\
\hline $\mathrm{F} 2$ & 100 & 15 & 10 & 50 & 70 \\
\hline F3 & 100 & 15 & 7.5 & 62.5 & 60 \\
\hline $\mathrm{F} 4$ & 100 & 10 & 7.5 & 62.5 & 65 \\
\hline F5 & 100 & 10 & 7.5 & 37.5 & 95 \\
\hline F6 & 100 & 15 & 5 & 50 & 75 \\
\hline F7 & 100 & 10 & 10 & 50 & 75 \\
\hline F8 & 100 & 12.5 & 10 & 62.5 & 60 \\
\hline F9 & 100 & 15 & 7.5 & 37.5 & 75 \\
\hline FIO & 100 & 12.5 & 5 & 37.5 & 90 \\
\hline FII & 100 & 12.5 & 5 & 62.5 & 65 \\
\hline $\mathrm{FI} 2$ & 100 & 12.5 & 10 & 37.5 & 85 \\
\hline $\mathrm{FI3}$ & 100 & 12.5 & 7.5 & 50 & 75 \\
\hline $\mathrm{FI} 4$ & 100 & 12.5 & 7.5 & 50 & 75 \\
\hline FI5 & 100 & 12.5 & 7.5 & 50 & 75 \\
\hline
\end{tabular}


three groups ( 6 animals/group). The first two groups received the optimized CVD-ODTs and the commercial tablets. The study was carried out using a crossover design with a washout period of 7 days between the two doses. During the first phase, rabbits received crushed tablets containing either the reference product (commercial tablet) or the test product (optimized formula of CVD-ODTs) suspended in water. In the second phase, rabbits that received the test product first were administered the reference product or vice versa. The reference product was administered orally in distilled water via a catheter. A third group was administered plain crushed tablets orally as a negative control.

\section{Sample collection}

Blood samples $(0.5 \mathrm{~mL})$ were withdrawn from the marginal ear vein of each rabbit at $0,0.5,1,1.5,2,4,6,8,10,12,18$, and 24 hours after oral administration of the test/reference product. Next, the blood samples were centrifuged at 3,500 rpm for 5 minutes and then analyzed by high-performance liquid chromatography (HPLC).

\section{Chromatographic conditions}

Determination of CVD in plasma was done using a modified HPLC method. ${ }^{25}$ An Agilent 1200 series HPLC apparatus (Agilent, Waldbronn, Germany) was used with a tandem mass spectrometry detector system. The mobile phase was a mixture of acetonitrile and $0.1 \%$ formic acid $(70: 30, \mathrm{v} / \mathrm{v})$ at a flow rate of $0.25 \mathrm{~mL}$ per minute.

\section{Pharmacokinetic analysis}

Pharmacokinetic parameters were estimated from the plasma data following oral administration of each of the two formulations. The maximum plasma concentration $\left(\mathrm{C}_{\max }\right)$ and time taken to reach maximum plasma concentration $\left(\mathrm{t}_{\max }\right)$, elimination rate constant $\left(\mathrm{K}_{\mathrm{e}}\right)$, half-life, mean residence time, and area under the plasma concentration-time curve $\left(\mathrm{AUC}_{0-\infty}\right)$ after oral administration were determined. The data are expressed as the mean \pm standard deviation and were analyzed using GraphPad Prism 6 (GraphPad Software, San Diego, CA, USA). Two-way analysis of variance followed by Sidak's multi-comparison were used to assess the difference and a $P$-value $<0.05$ was considered to be statistically significant.

\section{Results and discussion Solubility of CVD binary system}

The results of the saturation solubility studies are presented in Figure 1. The solubility of the pure drug in distilled water was found to be $7.323 \mathrm{mg} / \mathrm{mL}$. The solubility of CVD was improved after preparation of a solid dispersion using PVP (K30 and K90) in different ratios to reach $22.667 \mathrm{mg} / \mathrm{mL}$ for a PVP K90 1:3 (w/w) ratio. On the other hand, inclusion complexes of CVD with $\alpha-C D$ in $1: 2$ and $\beta$-CD in $1: 1$ and $1: 2$ molar ratios decreased the solubility of the drug to $3.584,5.255$, and $5.213 \mathrm{mg} /$ $\mathrm{mL}$, respectively. The CVD solubility improved more than three-fold after complexation with HP- $\beta-C D$ in a

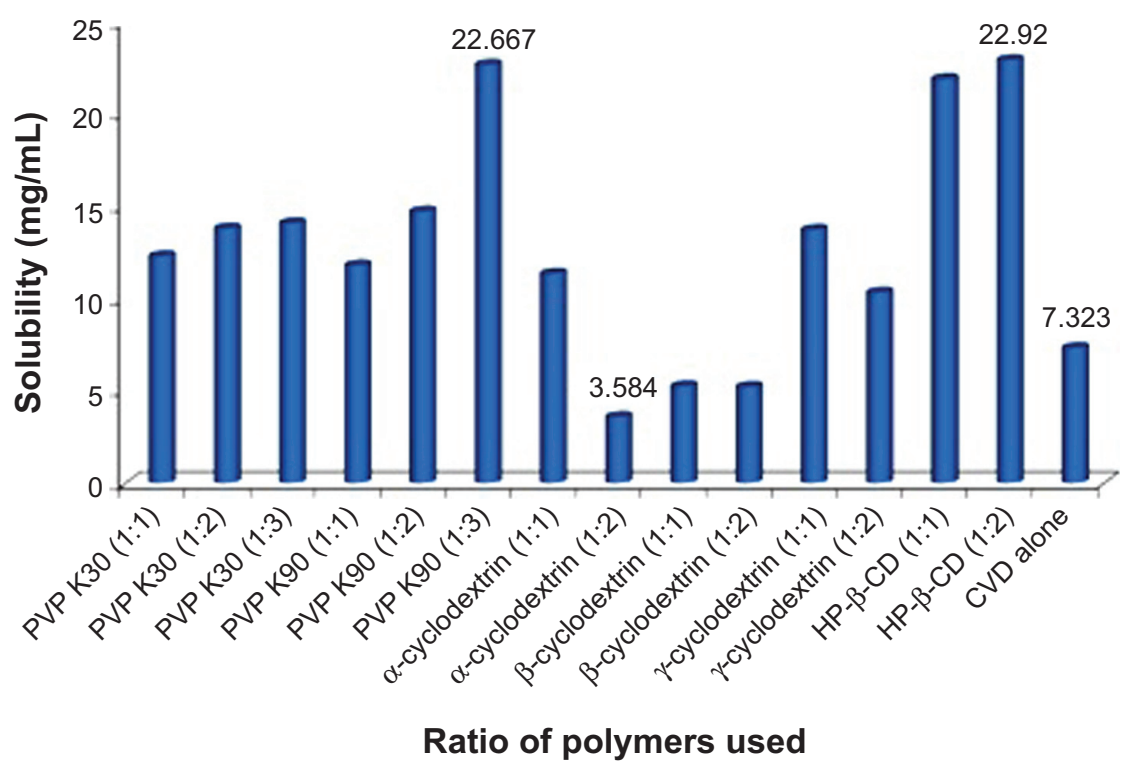

Figure I Solubility of CVD in solid dispersion and complexes with different polymers in different ratios. Values in the figure indicate highest and lowest solubility of binary complex compared with the raw CVD value.

Notes: Solid dispersion polymers used were PVP K30 and PVP K90 with average molecular weights of 44,000, and 360,000, respectively. CVD was complexed with $\alpha, \beta, \gamma$, and $\mathrm{HP}-\beta \mathrm{CD}$.

Abbreviations: PVP, polyvinyl pyrrolidone; HP, hydroxylpropyl; CD, cyclodextrin; CVD, carvedilol. 
1:2 molar ratio (Figure 1). These results indicate more improvement in CVD solubility when it was complexed with HP- $\beta-C D$ as compared with the other CD derivatives studied. This finding is attributed to the fact that the CVD molecule contains two well separated benzene groups which may individually complex with HP- $\beta-C D$. The availability of this appropriate geometry of CVD with HP- $\beta-C D$ in water causes the nonpolar aromatic portions of CVD to be more likely to enter the nonpolar cavity of the HP- $\beta$-CD molecule, thereby improving CVD aqueous solubility. ${ }^{26,27}$

\section{Differential scanning calorimetry}

The thermal behavior of pure CVD and the binary mixtures are shown in Figure 2. The differential scanning calorimetry thermogram of CVD indicates a sharp endothermic peak $\left(\mathrm{T}_{\text {peak }} 113.82^{\circ} \mathrm{C}\right)$ corresponding to its melting point, which is in agreement with values reported in the literature. ${ }^{28}$ However, this characteristic peak was retained in all the binary mixtures, but nearly disappeared in the thermogram for the HP- $\beta-C D$ complex, indicating that CVD forms an inclusion complex with HP- $\beta-C D$. These observations are again in agreement to those reported in the literature. ${ }^{29}$

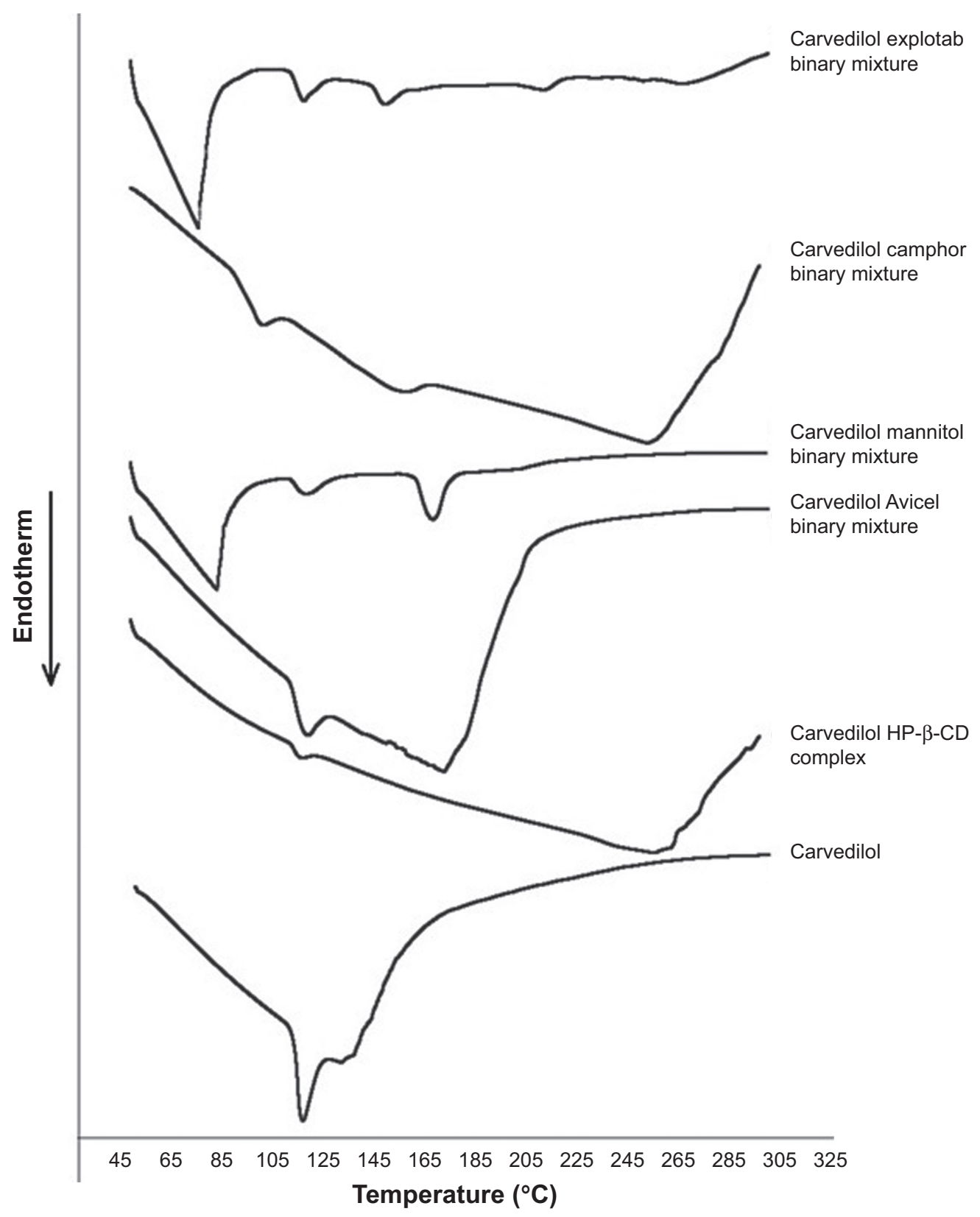

Figure 2 Differential scanning calorimetry thermograms of carvedilol and various binary systems. Abbreviations: HP, hydroxylpropyl; CD, cyclodextrin. 


\section{Fourier transform infrared spectroscopy}

The Fourier transform infrared spectra for CVD and the binary mixtures of CVD with Avicel, mannitol, camphor, and Explotab, as well as for the inclusion complex of CVD with HP- $\beta-C D$ in a 1:2 molar ratio are presented in Figure 3. Characterization of the inclusion complex by the infrared spectroscopy method showed that there was a difference in the spectrum for CVD and that for its inclusion complex with HP- $\beta-C D$. Specific absorbance of CVD is in the range of 3,500-3,000 $\mathrm{cm}^{-1}$ for vibration of N-H; 3,050-2,950 $\mathrm{cm}^{-1}$ for vibration of $\mathrm{C}-\mathrm{H} ; 1,600-1,480 \mathrm{~cm}^{-1}$ for vibration of aromatic $\mathrm{C}=\mathrm{C} ; 1,454-1,444 \mathrm{~cm}^{-1}$ for vibration of $\mathrm{C}-\mathrm{N} ; 1,403-1,256 \mathrm{~cm}^{-1}$ for vibration of the phenyl ring of C-C; and $1,040-800 \mathrm{~cm}^{-1}$ for vibration of substituted benzene rings for CVD. ${ }^{30}$ Significant differences were observed in the inclusion complex spectrum, for instance: aromatic $\mathrm{C}=\mathrm{C}$ vibration at $1,589.74 \mathrm{~cm}^{-1}$

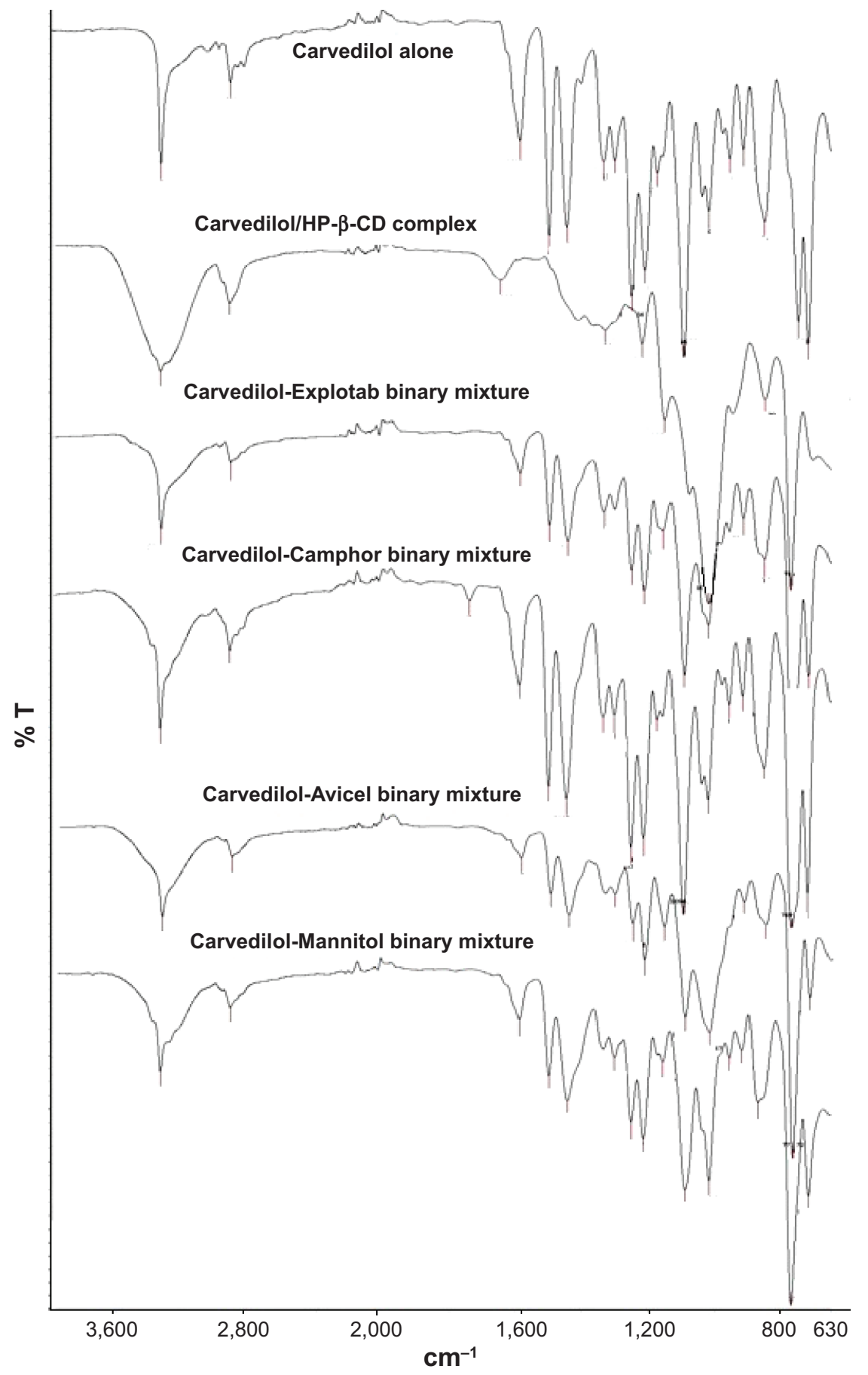

Figure 3 Fourier transform infrared spectra of carvedilol alone, with HP- $\beta-C D$ as a complex, and as binary mixtures with Explotab, camphor, Avicel, and mannitol. Abbreviations: HP, hydroxylpropyl; CD, cyclodextrin. 
and $1,502.21 \mathrm{~cm}^{-1}$ as well as the vibration of $\mathrm{C}-\mathrm{N}$ at $1,447.49 \mathrm{~cm}^{-1}$ were disappeared from the spectrum of the inclusion complex of CVD with HP- $\beta$-CD. In addition, the N-H vibration of the CVD HP- $\beta-C D$ complex at $3,340.79 \mathrm{~cm}^{-1}$ was slightly broadened and the band of the $\mathrm{CH}$ stretching region at $2,923.21 \mathrm{~cm}^{-1}$ was merged and broadened. The disappearance of vibration intensity in the CVD spectrum could have occurred as a result of the interaction between CVD with HP- $\beta-C D$ and formation of an inclusion complex that would disturb vibration. Generally, band broadening and merging can be explained by the possibility of intermolecular arrangements due to conversion of the sample from a crystalline state to an amorphous state. Moreover, it was found that there was no change in CVD diagnostic bands when mixed with ODTs excipients as binary mixtures (Figure 3). Accordingly, it can be postulated that only weak van der Waals or hydrogen forces are involved in binding of CVD to the excipients used in the preparation of ODTs.

\section{Evaluation of the prepared ODTs}

The prepared tablet formulations were evaluated for the different parameters to ensure uniformity and compatibility of the prepared tablets with compendial requirements (see Table 3 ). The weight of each tablet showed variability of no more than $1 \%$, which met the specification of the USP limits. The average weight of the 15 formulations was found to be in the range of 240.3-243.5 mg. Thickness, hardness, friability, and in vitro disintegration time of all the tablet formulations ranged from 3.178 to $3.290 \mathrm{~mm}, 4.412$ to $5.35 \mathrm{~kg} / \mathrm{cm}^{2}, 0.129 \%$ to $0.984 \%$, and 18 to 87 seconds, respectively. According to the European Pharmacopoeia, ODTs should disintegrate within 3 minutes, so all the prepared tablets met the pharmacopeial requirement. Friability for the CVD tablet formulations was less than $1.0 \%$. Drug content of all the formulations was in the range of $95.79 \%-104.40 \%$. These results support the reproducibility of the CVD formulation and tableting process used in this study.

\section{In vitro dissolution studies}

The in vitro dissolution results are presented in Figure 4. Sodium lauryl sulfate was added to the dissolution medium to maintain sink conditions and enhance the solubility of CVD at higher $\mathrm{pH}$, as recommended by the US Food and Drug Administration for lipophilic drugs. ${ }^{31}$ All formulations showed cumulative CVD release of at least $89.22 \%$ within 60 minutes. Thus, it can be concluded that the prepared CVD-ODTs are a better alternative to the currently used conventional CVD tablet.

\section{Kinetic treatment of the in vitro release data}

The goodness-of-fit method was used to study the release behavior of CVD from the different ODT formulations. In all formulations, zero-order equation showed higher correlation coefficient ( $\mathrm{r}$ ) compared with first-order and Higuchi's square-root of time equations (Table 4).

The highest release rate constant $(\mathrm{K})$ according to zeroorder kinetics was 1.57 per hour as shown in F6 (Table 4), which was related to the high tablet erosion rate during the dissolution test. The semi-empirical equation $\mathrm{M}_{\mathrm{t}} \mathrm{M}_{\infty}=\mathrm{Kt}^{\mathrm{n}}$ was used to determine the drug release mechanism. ${ }^{32}$ In all cases, the exponent " $n$ " ranged between 0.669 and 0.727 (Table 4). These values indicate non-Fickian or anomalous release, suggesting that release is controlled by a combination of diffusion and polymer relaxation.

Table 3 Characteristics of the orodispersible tablet formulations of carvedilol

\begin{tabular}{|c|c|c|c|c|c|c|}
\hline Formula & Weight (mg) & Thickness (mm) & Hardness $\left(\mathrm{kg} / \mathrm{cm}^{2}\right)$ & Friability (\%) & Drug content (\%) & Disintegration time (seconds) \\
\hline $\mathrm{FI}$ & $246.2 \pm 3.25$ & $3.20 \pm 0.00$ & $4.75 \pm 0.29$ & 0.354 & $95.79 \pm 0.04$ & $75.3 \pm 4.93$ \\
\hline $\mathrm{F} 2$ & $240.9 \pm I .44$ & $3.20 \pm 0.01$ & $4.77 \pm 0.39$ & 0.605 & $96.07 \pm 0.11$ & $18.0 \pm 2.64$ \\
\hline F3 & $240.5 \pm 1.26$ & $3.20 \pm 0.01$ & $5.13 \pm 0.38$ & 0.407 & $104.31 \pm 0.05$ & $41.0 \pm 2.64$ \\
\hline F4 & $242.9 \pm 2.13$ & $3.22 \pm 0.02$ & $5.21 \pm 0.45$ & 0.726 & $96.35 \pm 0.04$ & $67.0 \pm 4.0$ \\
\hline F5 & $24 I .3 \pm 1.56$ & $3.21 \pm 0.01$ & $4.5 I \pm 0.30$ & $0.46 \mathrm{I}$ & $104.6 \pm 0.05$ & $87.0 \pm 3.0$ \\
\hline F6 & $242.0 \pm 2.26$ & $3.21 \pm 0.01$ & $4.93 \pm 0.23$ & 0.139 & $104.4 \pm 0.04$ & $24.0 \pm 3.60$ \\
\hline F7 & $240.6 \pm 0.84$ & $3.23 \pm 0.01$ & $4.52 \pm 0.31$ & 0.476 & $95.97 \pm 0.05$ & $51.0 \pm 3.60$ \\
\hline F8 & $240.5 \pm 1.26$ & $3.23 \pm 0.02$ & $4.99 \pm 0.21$ & 0.259 & $96.35 \pm 0.11$ & $46.3 \pm 2.5 \mathrm{I}$ \\
\hline F9 & $24 I .1 \pm 0.99$ & $3.22 \pm 0.01$ & $4.53 \pm 0.35$ & 0.945 & $96.25 \pm 0.05$ & $26.0 \pm 4.0$ \\
\hline FIO & $242.7 \pm 2.7 \mid$ & $3.25 \pm 0.01$ & $4.62 \pm 0.44$ & 0.984 & $96.63 \pm 0.07$ & $47.0 \pm 5.0$ \\
\hline $\mathrm{FII}$ & $243.5 \pm 2.54$ & $3.23 \pm 0.01$ & $5.35 \pm 0.23$ & 0.129 & $103.9 \pm 0.04$ & $65.3 \pm 3.06$ \\
\hline $\mathrm{FI} 2$ & $243.0 \pm 4.52$ & $3.18 \pm 0.33$ & $4.4 I \pm 0.18$ & 0.843 & $103.9 \pm 0.07$ & $64.0 \pm 2.0$ \\
\hline $\mathrm{FI} 3$ & $242.4 \pm 1.77$ & $3.27 \pm 0.0 \mathrm{I}$ & $4.83 \pm 0.21$ & 0.680 & $101.1 \pm 0.07$ & $55.0 \pm 3.0$ \\
\hline $\mathrm{FI} 4$ & $242.2 \pm 1.87$ & $3.26 \pm 0.01$ & $4.79 \pm 0.16$ & 0.678 & $102.7 \pm 0.28$ & $58.0 \pm 5.56$ \\
\hline FI5 & $240.3 \pm 0.94$ & $3.29 \pm 0.01$ & $4.7 I \pm 0.18$ & 0.665 & $101.1 \pm 0.07$ & $53.0 \pm 1.73$ \\
\hline
\end{tabular}

Notes: Data are expressed as the mean \pm standard deviation $(n=10)$. 


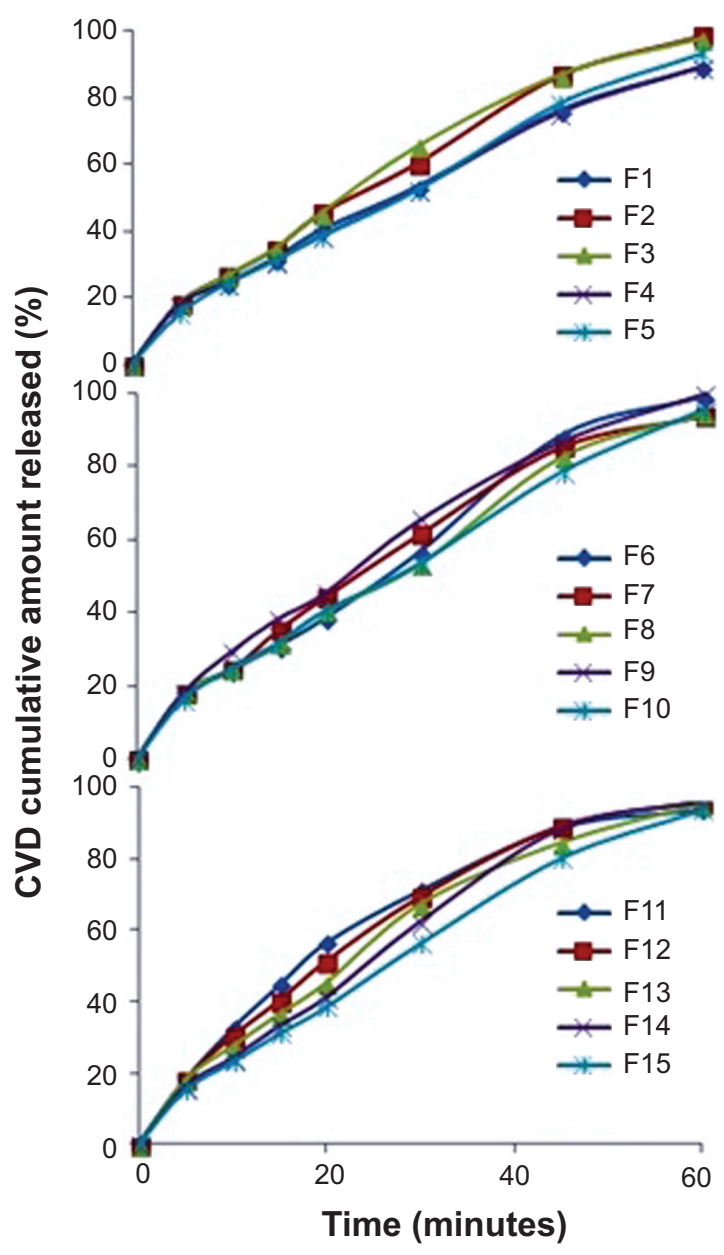

Figure 4 In vitro release profiles for CVD-ODT formulations prepared according to a Box-Behnken design. As a result of overlapping, error bars are omitted for clarity. Abbreviations: CVD, carvedilol; ODT, orodispersible tablet.

\section{Response surface methodology for optimization of CVD-ODTs}

A three-factor, three-level BBD was constructed to evaluate the effects of the ingredients in the formulation on the hardness, disintegration time, and in vitro release of CVD from ODTs. Statistical analysis of BBD batches was performed to estimate the quantitative effects of the factors $\mathrm{X}_{1}-\mathrm{X}_{3}$. Two-way analysis of variance and factors, estimated effects of factors and associated $P$-values for $\left(\mathrm{Y}_{1}-\mathrm{Y}_{3}\right)$ are presented in Table 5 . According to these results, $X_{1}$ had no significant effect on $Y_{1}$, but had a significant antagonistic effect on $\mathrm{Y}_{2}(P=0.0001)$ and a significant synergistic effect on $\mathrm{Y}_{3}(P=0.0002)$. Also, it was found that $\mathrm{X}_{2}$ had a significant antagonistic effect only on $\mathrm{Y}_{1}$ $(P=0.0137)$. On the other hand, $X_{3}$ has a significant synergistic effect on $Y_{1}(P=0.0002)$ and a significant antagonistic effect on $\mathrm{Y}_{3}(P=0.0240)$, with no significant effect on $\mathrm{Y}_{2}$. In addition, $\mathrm{Y}_{2}$ was significantly affected by the antagonistic effects of $\mathrm{X}_{1}$, the interaction term $\mathrm{X}_{2} \mathrm{X}_{3}$ and the quadratic term of $\mathrm{X}_{1}$ and $\mathrm{X}_{2}$ ( $P=0.0001, P=0.0132, P=0.0417$, and $P=0.0470$, respectively). Whereas, $\mathrm{Y}_{2}$ was significantly affected by the synergistic effect of the interaction term $\mathrm{X}_{1} \mathrm{X}_{3}$ and the quadratic term of $\mathrm{X}_{3}$ with $P=0.0147$ and $P=0.0434$, respectively.

The values for the responses $\left(\mathrm{Y}_{1}-\mathrm{Y}_{3}\right)$ of the ODTs were analyzed using Statgraphics Plus For Windows software and the mathematical model for each response was generated. The results of the multiple linear regression analysis for each response variable derived by the best fit method are shown in Equations 2-4:

Table 4 Kinetic treatment of the orodispersible tablet formulations of carvedilol

\begin{tabular}{|c|c|c|c|c|c|}
\hline \multirow[t]{2}{*}{ Formulation } & \multicolumn{3}{|l|}{$\mathbf{r}$} & \multirow{2}{*}{$\frac{\mathrm{n}}{\text { Korsmeyer }}$} & \multirow[t]{2}{*}{ K (per hour) } \\
\hline & Zero-order & First-order & Higuchi & & \\
\hline $\mathrm{FI}$ & 0.997 & -0.984 & 0.992 & 0.669 & 1.335 \\
\hline F2 & 0.993 & -0.938 & 0.988 & 0.702 & 1.511 \\
\hline F3 & 0.992 & -0.956 & 0.988 & 0.701 & I.497 \\
\hline F4 & 0.997 & $-0.98 \mathrm{I}$ & 0.990 & 0.673 & 1.342 \\
\hline F5 & 0.985 & -0.971 & 0.977 & 0.712 & 1.500 \\
\hline F6 & 0.990 & $-0.94 I$ & 0.978 & 0.727 & 1.574 \\
\hline F7 & 0.983 & -0.969 & 0.975 & 0.713 & 1.506 \\
\hline F8 & 0.986 & -0.972 & 0.979 & 0.710 & 1.500 \\
\hline F9 & 0.994 & -0.900 & 0.988 & 0.704 & 1.530 \\
\hline FIO & 0.986 & $-0.97 \mid$ & 0.979 & 0.713 & 1.516 \\
\hline FII & 0.984 & $-0.97 \mid$ & 0.978 & 0.709 & 1.497 \\
\hline $\mathrm{FI} 2$ & 0.987 & -0.970 & 0.980 & 0.715 & 1.530 \\
\hline $\mathrm{FI} 3$ & 0.990 & -0.970 & 0.980 & 0.714 & 1.520 \\
\hline $\mathrm{FI} 4$ & 0.990 & -0.970 & 0.980 & 0.720 & 1.530 \\
\hline FI5 & 0.985 & -0.970 & 0.976 & 0.712 & 1.503 \\
\hline
\end{tabular}

Notes: $r$, correlation coefficient; $n$, drug release mechanism regression; $K$, zero-order release rate constant. 
Table 5 Estimated effects of factors and associated $P$-values for $\left(Y_{1}-Y_{3}\right)$ responses

\begin{tabular}{|c|c|c|c|c|c|c|}
\hline \multirow[t]{2}{*}{ Factor } & \multicolumn{2}{|l|}{$\mathbf{Y}_{1}$} & \multicolumn{2}{|l|}{$\underline{\mathbf{Y}_{2}}$} & \multicolumn{2}{|l|}{$\mathbf{Y}_{3}$} \\
\hline & Factor effect & $P$-value & Factor effect & $P$-value & Factor effect & $P$-value \\
\hline$X_{1}$ & 0.093 & 0.2107 & -42.75 & $0.000 I^{*}$ & 7.28 & $0.0002 *$ \\
\hline $\mathrm{X}_{2}$ & -0.24 & $0.0137^{*}$ & -8.00 & 0.0648 & 1.43 & 0.1011 \\
\hline $\mathrm{X}_{3}$ & 0.653 & $0.0002^{*}$ & -1.25 & 0.7274 & -2.29 & $0.0240 *$ \\
\hline$X_{1}{ }^{2}$ & -0.032 & 0.7521 & -13.58 & $0.0417^{*}$ & 0.50 & 0.6516 \\
\hline$x_{1} x_{2}$ & 0.035 & 0.7168 & 9.00 & 0.1193 & -2.20 & 0.0817 \\
\hline$X_{1} X_{3}$ & -0.05 & 0.6069 & 17.5 & $0.0147^{*}$ & 1.09 & 0.3296 \\
\hline$X_{2}^{2}$ & -0.037 & 0.7150 & -13.08 & $0.0470^{*}$ & -0.13 & 0.9093 \\
\hline $\mathrm{X}_{2} \mathrm{X}_{3}$ & -0.075 & $0.448 I$ & -18.00 & $0.0132^{*}$ & -0.13 & 0.9026 \\
\hline$X_{3}^{2}$ & 0.168 & 0.1362 & 13.42 & $0.0434^{*}$ & -0.16 & 0.8843 \\
\hline
\end{tabular}

Note: *Significant effect of factors on individual responses.

Abbreviations: $X_{1}$, percentage of Explotab; $X_{2}$, percentage of camphor; $X_{3}$, percentage of Avicel; $Y_{1}$, hardness of the prepared tablets; $Y_{2}$, disintegration time; $Y_{3}$, cumulative amount of drug released after one hour.

$$
\begin{aligned}
\operatorname{Hardness}\left(\mathrm{Y}_{1}\right)= & 3.699+0.252 \mathrm{X}_{1}+0.053 \mathrm{X}_{2}- \\
& 0.022 \mathrm{X}_{3}-0.016 \mathrm{X}_{1}^{2}+0.018 \mathrm{X}_{1} \mathrm{X}_{2}- \\
& 0.005 \mathrm{X}_{1} \mathrm{X}_{3}-0.018 \mathrm{X}_{2}^{2}- \\
& 0.008 \mathrm{X}_{2} \mathrm{X}_{3}+0.003 \mathrm{X}_{3}^{2}
\end{aligned}
$$

Disintegration time $\left(\mathrm{Y}_{2}\right)=189.875-1.958 \mathrm{X}_{1}+48.75 \mathrm{X}_{2}-$ $14.208 \mathrm{X}_{3}-6.792 \mathrm{X}_{1}^{2}+$ $4.5 \mathrm{X}_{1} \mathrm{X}_{2}+1.75 \mathrm{X}_{1} \mathrm{X}_{3}-$ $6.542 \mathrm{X}_{2}^{2}-1.8 \mathrm{X}_{2} \mathrm{X}_{3}+$ $0.268 \mathrm{X}_{3}^{2}$

In vitro release $\left(\mathrm{Y}_{3}\right)=77.185+2.233 \mathrm{X}_{1}+6.841 \mathrm{X}_{2}-$ $0.606 \mathrm{X}_{3}+0.252 \mathrm{X}_{1}^{2}-1.098 \mathrm{X}_{1} \mathrm{X}_{2}+$ $0.109 \mathrm{X}_{1} \mathrm{X}_{3}-0.063 \mathrm{X}_{2}^{2}-$ $0.013 \mathrm{X}_{2} \mathrm{X}_{3}-0.003 \mathrm{X}_{3}^{2}$

Equations 1-3 reflect the quantitative influence of the formulation variables, ie, percentage superdisintegrant $\left(\mathrm{X}_{1}\right)$, percentage subliming agent $\left(\mathrm{X}_{2}\right)$, and percentage binder $\left(\mathrm{X}_{3}\right)$, and their interactions on the responses, ie, hardness $\left(\mathrm{Y}_{1}\right)$, disintegration time $\left(\mathrm{Y}_{2}\right)$, and in vitro release $\left(\mathrm{Y}_{3}\right)$.

Pareto charts and main effects plots (Figure 5) are used to demonstrate the effect (in decreasing order of importance) of the independent variables and their interactions on the dependent variables. The chart includes a vertical reference line at the critical $P$-value of 0.05 . An effect that exceeds the vertical line is considered to be statistically significant. The fact that the bar for the variable $\mathrm{X}_{1}$ extends after the reference line and has a relatively larger coefficient in the regression equations for both $\mathrm{Y}_{2}$ and $\mathrm{Y}_{3}$. As shown in Figure 5, $\mathrm{X}_{1}$ has an antagonistic effect on the disintegration time $\left(\mathrm{Y}_{2}\right)$ and a synergistic effect on in vitro release $\left(\mathrm{Y}_{3}\right)$. On the other hand, the variable $\mathrm{X}_{2}$ has a significant effect only on the hardness of the tablets $\left(\mathrm{Y}_{1}\right)$ and its quadratic term has a significant effect on the disintegration time $\left(\mathrm{Y}_{2}\right)$. The variable $\mathrm{X}_{3}$ has a significant effect on $\mathrm{Y}_{1}$ and $\mathrm{Y}_{3}$, indicating that the binder percentage (Avicel) has a significant effect in increasing both tablet hardness and decreasing the in vitro release of CVD from the ODTs after 60 minutes.

\section{Effects on hardness $\left(Y_{1}\right)$}

The $Y_{1}$ response ranged from $4.41 \mathrm{~kg} / \mathrm{cm}^{2}$ for $F 12$ to $5.35 \mathrm{~kg} / \mathrm{cm}^{2}$ for F11, as shown in Table 3. It was found that $\mathrm{X}_{3}$ has the main effect on determining the hardness of the formulation, as seen in the main effect plot for $\mathrm{Y}_{1}$ (Figure 5). A direct relationship was found between $X_{3}$ and $Y_{1}$. Increasing $X_{3}$ from $15 \%$ to $25 \%$ increased $Y_{1}$ for the CVD-ODTs from $4.51 \mathrm{~kg} / \mathrm{cm}^{2}$ in $\mathrm{F} 5$ to $5.21 \mathrm{~kg} / \mathrm{cm}^{2}$ in $\mathrm{F} 4$ and from $4.41 \mathrm{~kg} /$ $\mathrm{cm}^{2}$ in F12 to $4.99 \mathrm{~kg} / \mathrm{cm}^{2}$ in F8. This may be explained by the increase in binding effect of Avicel, which is in agreement with previous work. ${ }^{33,34}$ On the other hand, an inverse relationship was found between $\mathrm{X}_{2}$ and $\mathrm{Y}_{1}$, ie, an increase in $X_{2}$ percent will decrease $Y_{1}$. This finding was deduced from the increase in $Y_{1}$ from $4.77 \mathrm{~kg} / \mathrm{cm}^{2}$ to $4.93 \mathrm{~kg} / \mathrm{cm}^{2}$ with the decrease of $\mathrm{X}_{2}$ from $4 \%$ to $2 \%$. This finding can be verified by the results of F1 and F7 that have a hardness of $4.75 \mathrm{~kg} / \mathrm{cm}^{2}$ and $4.52 \mathrm{~kg} / \mathrm{cm}^{2}$, respectively. This may be attributed to the presence of camphor in high concentration that increases the porosity of the tablets and consequently decreases the hardness of the tablets produced. ${ }^{35-37}$ Finally, the rest of the variables, their interactions, and the quadratic terms have no significant effects on hardness $\left(\mathrm{Y}_{1}\right)$.

\section{Effects on disintegration time $\left(\mathrm{Y}_{2}\right)$}

The $\mathrm{Y}_{2}$ response ranged from 18 seconds in $\mathrm{F} 2$ to 87 seconds in F5, as shown in Table 3. It was found that $\mathrm{X}_{1}$ was the main factor responsible for the difference in disintegrating times of the formulations, as displayed in the main effect plot for $\mathrm{Y}_{2}$ (Figure 5). There was an inverse 

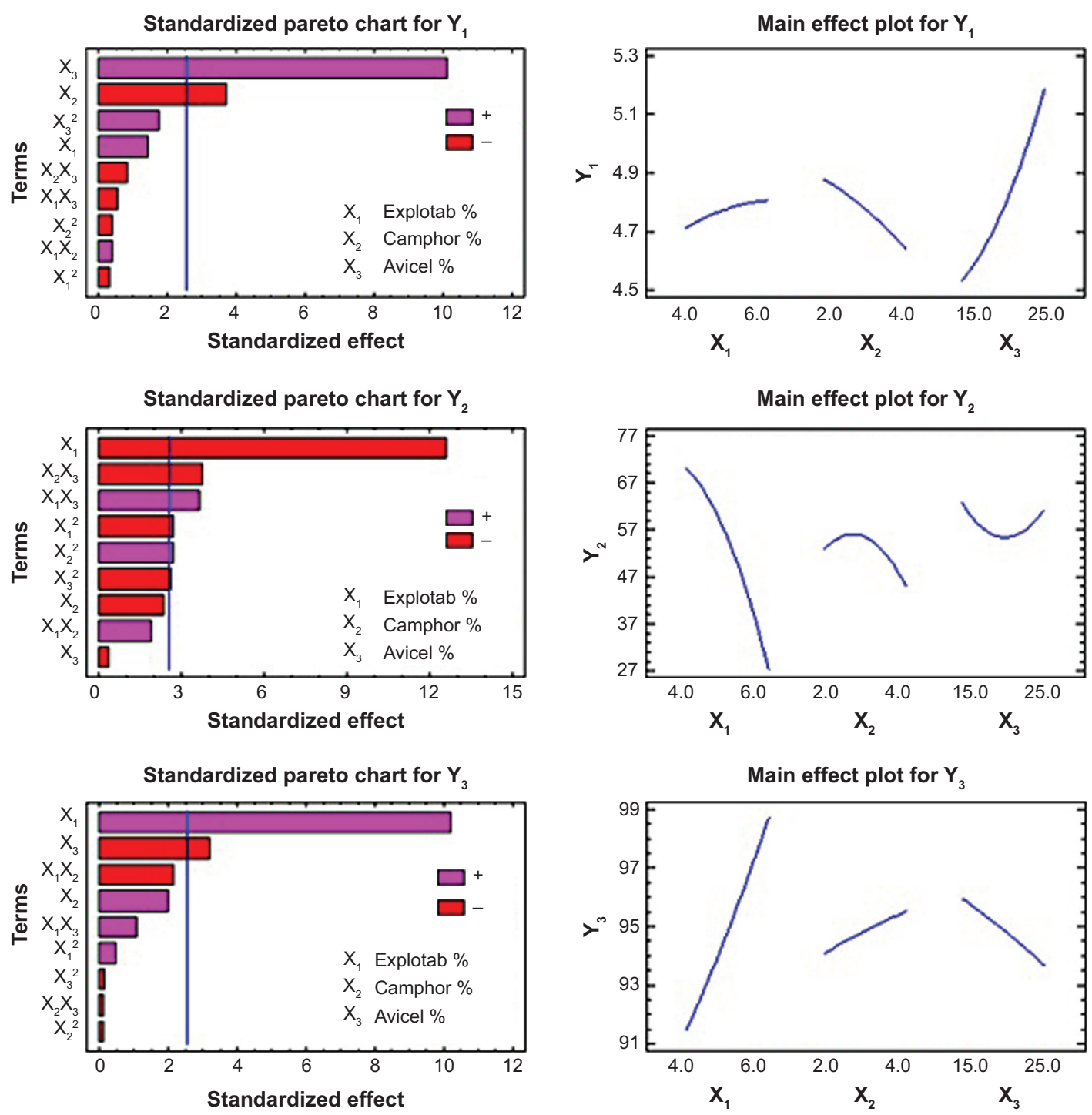

Figure 5 Standardized Pareto charts and main effect plots for $Y_{1}, Y_{2}$ and $Y_{3}$. Abbreviations: $Y_{1}$, hardness of the prepared tablets; $Y_{2}$, disintegration time; $Y_{3}$, cumulative amount of drug released after one hour.

relationship between $\mathrm{X}_{1}$ and $\mathrm{Y}_{2}$. As $\mathrm{X}_{1}$ increased from $4 \%$ to $6 \%, \mathrm{Y}_{2}$ decreased from 75 seconds (F1) to 24 seconds (F6), from 51 seconds (F7) to 18 seconds (F2), and from 67 seconds (F4) to 41 seconds (F3). From these results, it is obvious that the increase in $\mathrm{X}_{1}$ markedly decreases $\mathrm{Y}_{2}$, and that could be attributed to the ability of Explotab to swell in the prepared formulations; Explotab absorbs water rapidly, resulting in swelling that leads to rapid disintegration of tablets. ${ }^{38}$ Finally, the results revealed that $\mathrm{Y}_{2}$ is significantly affected by the interaction terms $\mathrm{X}_{2} \mathrm{X}_{3}, \mathrm{X}_{1} \mathrm{X}_{3}$, and the quadratic terms of $X_{1}, X_{2}$, and $X_{3}$.

\section{Effects on the cumulative \% release $\left(\mathrm{Y}_{3}\right)$}

The in vitro dissolution data for all the CVD-ODT formulations are shown in Figure 4. It is evident from the dissolution profiles that all formulations had a rapid and complete dissolution profile. The $\mathrm{Y}_{3}$ response ranged from $89.22 \%$ in $\mathrm{F} 1$ to $99.72 \%$ in F5, as seen in Figure 4 . $\mathrm{X}_{1}$ and $\mathrm{X}_{3}$ were found to have the main effect on determining release of CVD from the ODTs. There was a direct relationship between $\mathrm{X}_{1}$ and $\mathrm{Y}_{3}$. As the percentage of $\mathrm{X}_{1}$ increased from $4 \%$ to $6 \%, \mathrm{Y}_{3}$ increased from $89.22 \%$ in $\mathrm{F} 1$ to $98.69 \%$ in F6, from $93.61 \%$ in $\mathrm{F} 7$ to $98.69 \%$ in $\mathrm{F} 2$, and from $89.26 \%$ in F4 to $97.64 \%$ in F3. From these results, the increase in $\mathrm{X}_{1}$ markedly increased the release of CVD from ODTs. This could be related to Explotab's porous structure that allows highest water absorption ratio, rapid rate of water uptake, and enhanced wetting of tablets. ${ }^{39}$ In contrast, when $\mathrm{X}_{3}$ increased from $15 \%$ to $25 \%, \mathrm{Y}_{3}$ decreased from $99.72 \%$ in $\mathrm{F} 9$ to $97.64 \%$ in $\mathrm{F} 3$, from $93.52 \%$ in $\mathrm{F} 5$ to $89.26 \%$ in $\mathrm{F} 4$, 
and from $95.02 \%$ in F10 to $93.75 \%$ in F11, which can be attributed to the increased tablet hardness resulting from the increase in percentage of Avicel in the formulation. This prolongs the disintegration time and subsequently reduces the amount of drug released. Three-dimensional response surface plots and the contours of these estimated response surfaces (Figure 6) were determined graphically using the software to understand the relationship between the studied factors and the obtained responses.

\section{Prediction of the optimized formulation}

Analysis of experimental parameters was carried out to compromise the studied responses in order to reach an optimium combination of factor levels. Accordingly, this combination
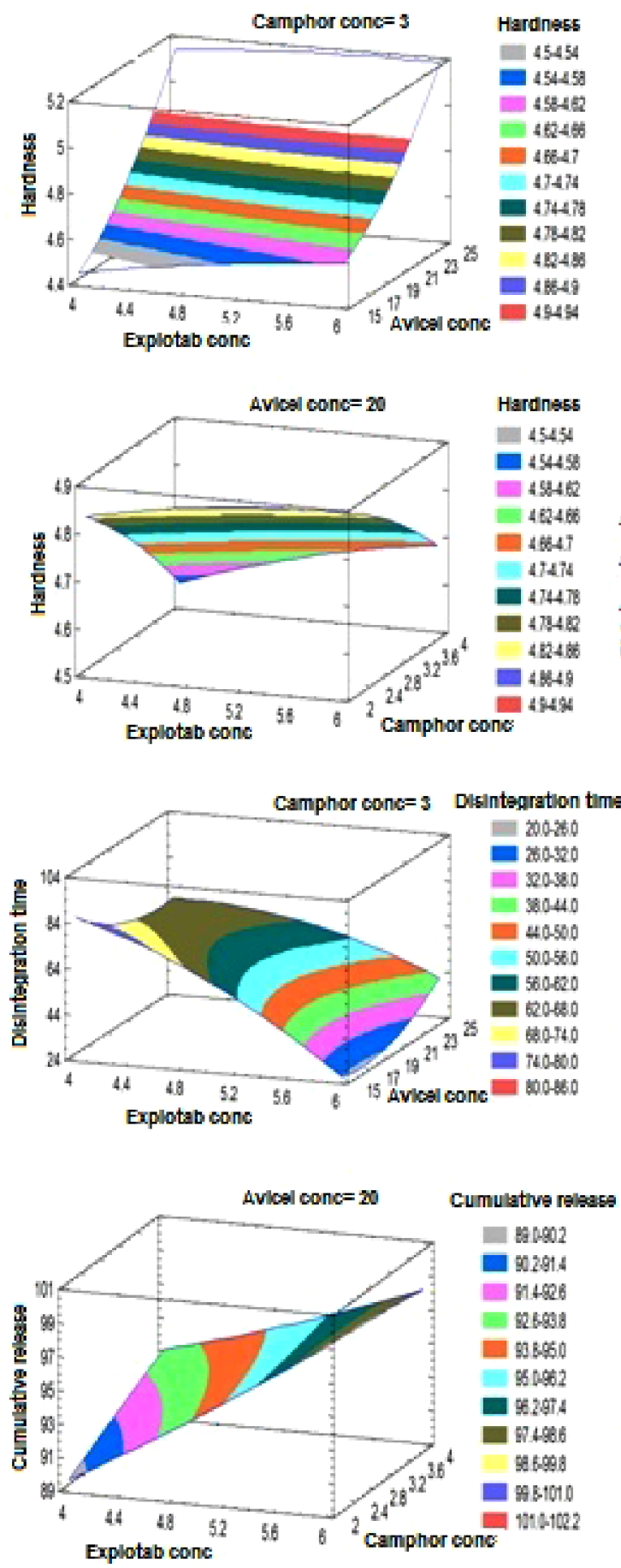
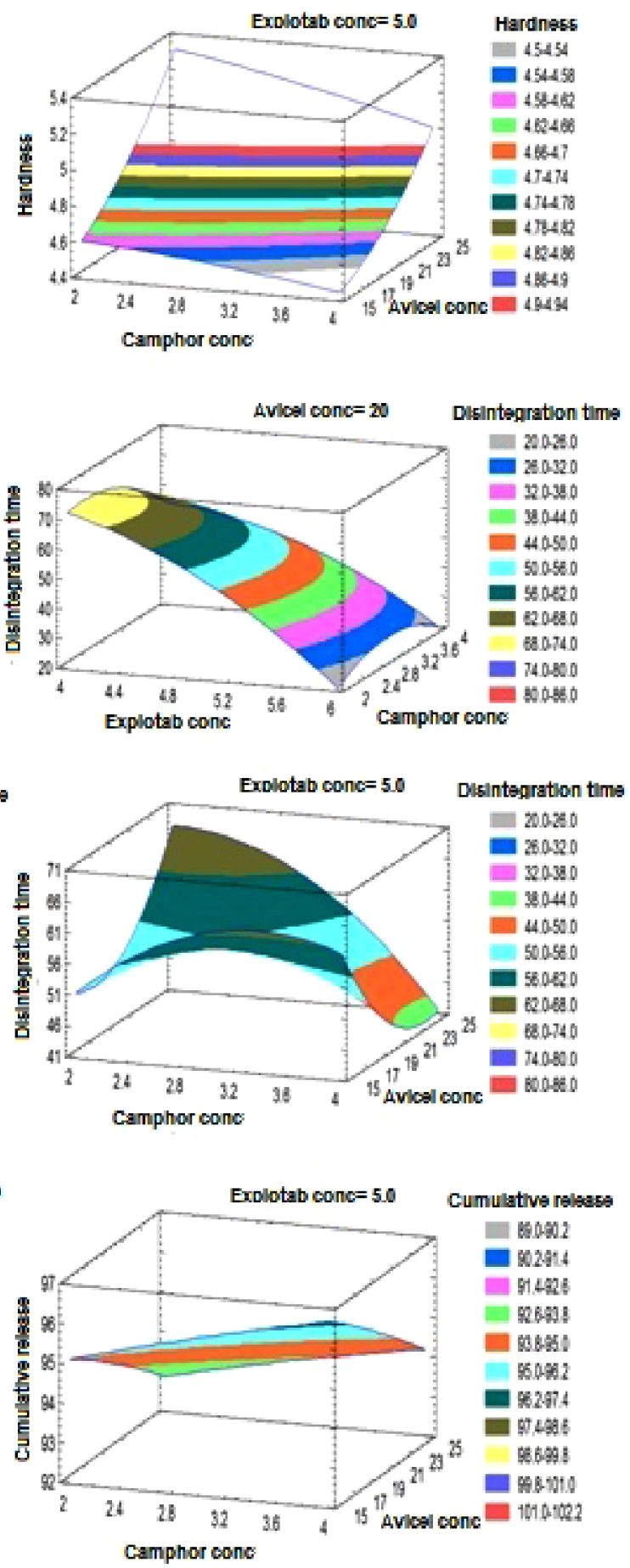

Figure 6 Estimated response surfaces with contour plots showing the effects of $X_{1}, X_{2}$, and $X_{3}$ on the dependent variables $\left(Y_{1}-Y_{3}\right)$

Abbreviations: $X_{1}$, percentage of Explotab; $X_{2}$, percentage of camphor; $X_{3}$, percentage of Avicel; $Y_{1}$, hardness of the prepared tablets; $Y_{2}$, disintegration time; $Y_{3}$, cumulative amount of drug released after one hour. 
Table 6 Optimal calculated variables and observed, predicted and residual values for responses

\begin{tabular}{llllll}
\hline Variables & Optimum & Responses & Predicted & Observed & Residuals \\
\hline Percentage Explotab & 5.99 & Hardness $\left(\mathrm{kg} / \mathrm{cm}^{2}\right)$ & 5.18 & 5.27 & -0.09 \\
Percentage camphor & 2.0 & Disintegration time (seconds) & 32.09 & 31.33 & 0.76 \\
Percentage Avicel & 23.63 & Release at one hour (\%) & 98.65 & 98.70 & -0.05 \\
\hline
\end{tabular}

will maximize the desirability function over the indicated region of the obtained data. To confirm the validity of the calculated optimal parameters and the predicted responses, the responses at optimal combination of independent factors were carried out. Table 6 illustrates the optimal calculated parameters, the observed and predicted responses, and the residual values for the responses. From these results, it can be concluded that the optimized combination of independent factors ensured the desired hardness, disintegration time, and drug release profile. In addition, this finding verified the reliability of the optimization procedure with regard to maximizing the hardness of the ODTs, shortening the disintegration time to fulfill pharmacopeial requirements, and improving the amount of CVD released within 60 minutes via the direct compression method.

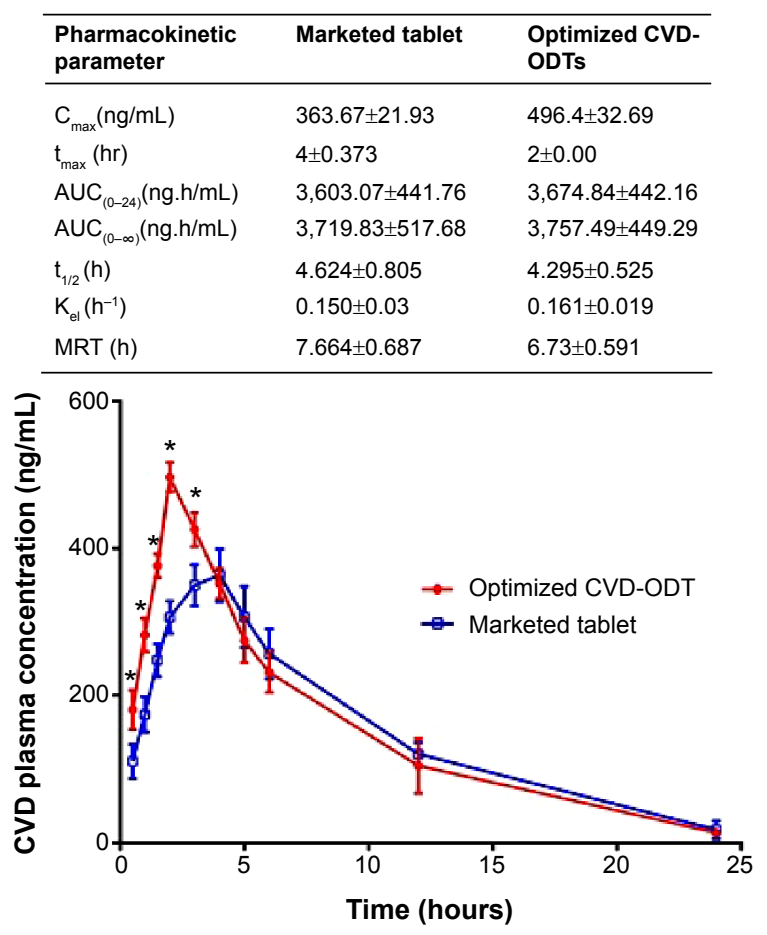

Figure 7 Mean plasma concentration-time profiles for CVD and pharmacokinetic parameters (inset) after oral administration of a single dose $(2.5 \mathrm{mg} / \mathrm{kg})$ of the marketed tablet and the CVD-ODT formulations.

Notes: Data represent the mean value \pm standard deviation $(n=6)$.

Abbreviations: CVD, carvedilol; ODT, orodispersible tablet; AUC, area under the time-concentration curve; $\mathrm{C}_{\text {max }}$, maximum plasma concentration; $\mathrm{K}_{\mathrm{el}}$, elimination rate constant; MRT, mean residence time; SMV, simvastatin; $\mathrm{t}_{1 / 2}$, half-life; $\mathrm{T}_{\max }$, time to reach $\mathrm{C}_{\max }$.

\section{In vivo and pharmacokinetic evaluation in rabbits}

An in vivo study was done to compare the pharmacokinetics of CVD from the optimized ODT formulation with those of the marketed CVD tablet. A single dose of CVD $(2.5 \mathrm{mg} / \mathrm{kg})$ was given to New Zealand white rabbits according to a double-blind, randomized, crossover design.

The mean plasma concentration-time profiles of CVD after oral administration of a single dose $(2.5 \mathrm{mg} / \mathrm{kg})$ of the optimized CVD-ODT formulation and the marketed tablet are shown in Figure 7. $\mathrm{C}_{\max }, \mathrm{t}_{\max }, \mathrm{AUC}_{0-24}$, half-life, $\mathrm{K}_{\mathrm{el}}$, and mean residence time for CVD from these formulations are summarized in the inset table of Figure 7.

The results indicated that the bioavailability (F) of the ODT formulation when compared with that of the marketed tablet was $101.992 \%$. These data indicate that the ODT slightly improved the bioavailability of CVD in comparison with the marketed tablet. On the other hand, the in vivo data showed that the oral absorption of CVD from the ODT formulation was markedly higher than that of the marketed tablet as a result of the significant improvement in $\mathrm{C}_{\max }$ from 363.667 to 496.4 $\mathrm{ng} / \mathrm{mL}$ for the marketed tablet and the optimized CVD-ODT formulation, respectively. Moreover, the $t_{\max }$ of the ODT decreased to 2 hours, compared with the $t_{\max }$ of 4 hours for the marketed tablet. This leads to acceleration of the onset of action for the ODT when compared with the marketed tablet.

Analysis of variance showed significant $(P<0.0001)$ differences between samples taken from the two groups of rabbits during the absorption phase at $0.5,1,1.5,2$, and 3 hours, indicating significant enhancement achieved by the ODT. The inclusion complex of CVD with HP- $\beta-C D$ formulated as oral disintegrating tablets allows for higher apparent solubility, thereby increasing both the dissolution rate and the concentration of drug available for absorption..$^{40}$ Based on these results, the inclusion complex of CVD with HP- $\beta-C D$ as well as its formulation as an ODT is a promising method for enhancing the solubility and oral absorption of CVD.

\section{Conclusion}

The results of this study showed that preparation of solid binary systems of CVD with HP- $\beta$-CD in a molar ratio of 1:2 improves drug solubility by more than three-fold. BBD 
was used to evaluate the independent variables producing optimum ODT properties. The percentage of the superdisintegrant (sodium starch glycolate) had the main effect in achieving the desired tablet properties, in addition to the subliming agent (camphor) used and the concentration of the incorporated binder (Avicel). Optimized combination of independent factors maximized the hardness of the ODT, shortened the disintegration time to fulfill pharmacopeial requirements and increased the amount of CVD released within 60 minutes. Comparison of the pharmacokinetics of the optimized CVD-ODT with that of the marketed tablet in healthy rabbits showed a significant improvement in the onset of action of CVD after oral administration of the optimized formulation due to enhancement of drug solubility and subsequently accelerated drug absorption.

\section{Disclosure}

The authors report no conflicts of interest in this work.

\section{References}

1. Stafylas PC, Sarafidis PA. Carvedilol in hypertension treatment. Vasc Health Risk Manag. 2008;4(1):23-30.

2. World Health Organization. The Selection and Use of Essential Medicines, WHO Expert Committee Report, 2011. Available from: http:/ www.who.int/selection_medicines/committees/expert/17/en/. Accessed January 28, 2015.

3. Chakraborty S, Shukla D, Jain A, Mishra B, Singh S. Assessment of solubilization characteristics of different surfactants for carvedilol phosphate as a function of pH. J Colloid Interface Sci. 2009;335(2):242-249.

4. Neugebauer G, Akpan W, Kaufmann B, Reiff K. Stereoselective disposition of carvedilol in man after intravenous and oral administration of the racemic compound. Eur J Clin Pharmacol. 1990;38(2):108-111.

5. Morgan T. Clinical pharmacokinetics and pharmacodynamics of carvedilol. Clin Pharmacokinet. 1994;26(5):335-346.

6. Takagi T, Ramachandran C, Bermejo M, Yamashita S, Yu LX, Amidon GL. A provisional biopharmaceutical classification of the top 200 oral drug products in the United States, Great Britain, Spain, and Japan. Mol Pharm. 2006;3(6):631-643.

7. Wei L, Sun P, Nie S, Pan W. Preparation and evaluation of SEDDS and SMEDDS containing carvedilol. Drug Dev Ind Pharm. 2005; 31(8):785-794.

8. Mahmoud EA, Bendas ER, Mohamed MI. Preparation and evaluation of self-nanoemulsifying tablets of carvedilol. AAPS Pharm Sci Tech. 2009;10(1):183-192.

9. Pamudji JS, Mauludin R, Lestari VA. Improvement of carvedilol dissolution rate through formation of inclusion complex with $\beta$-cyclodextrin. Int J Pharm Pharm Sci. 2014;6(4):2-7.

10. Yamsani V, Gannu R, Kolli C, Rao M, Yamsani M. Development and in vitro evaluation of buccoadhesive carvedilol tablets. Acta Pharm. 2007;57(2):185-197.

11. Vishnu V, Chandrasekhar K, Ramesh G, Rao MY. Development of mucoadhesive patches for buccal administration of carvedilol. Curr Drug Deliv. 2007;4(1):27-39.

12. Nolte K, Backfisch G, Neidlein R. In vitro absorption studies with carvedilol using a new model with porcine intestine called BM-RIMO (BoehringerMannheim ring model). Arzneimittelforschung. 1999;49(09):745-749.

13. Valleri M, Mura P, Maestrelli F, Cirri M, Ballerini R. Development and evaluation of glyburide fast dissolving tablets using solid dispersion technique. Drug Dev Ind Pharm. 2004;30(5):525-534.
14. Karavas E, Ktistis G, Xenakis A, Georgarakis E. Effect of hydrogen bonding interactions on the release mechanism of felodipine from nanodispersions with polyvinylpyrrolidone. Eur J Pharm Biopharm. 2006;63(2):103-114.

15. Tenjarla S, Puranajoti P, Kasina R, Mandal T. Preparation, characterization, and evaluation of miconazole-cyclodextrin complexes for improved oral and topical delivery. J Pharm Sci. 1998;87(4):425-429.

16. Modi A, Tayade P. Enhancement of dissolution profile by solid dispersion (kneading) technique. AAPS Pharm Sci Tech. 2006;7(3):68.

17. Higuchi T, Connors A. Phase-solubility techniques. In: Advances in Analytical Chemistry Instrumentation. New York, NY, USA: Wiley Interscience; 1965.

18. The United States Pharmacopoeia, The National Formulary (USP 28/ NF23), USP Convention INC., Rockville, MD, 2005: 2411-2503.

19. Wagner J. Interpretation of percent dissolved-time plots derived from in vitro testing of conventional tablets and capsules. J Pharm Sci. 1969; 58:1253-1257.

20. Desai SJ, Singh P, Simonelli AP, Higuchi W. Investigation of factors influencing release of solid drug dispersed in inert matrices III. Quantitative studies involving the polyethylene plastic matrix. J Pharm Sci. 1966;55(11):1230-1234.

21. Higuchi T. Mechanism of sustained-action medication. Theoretical analysis of rate of release of solid drugs dispersed in solid matrices. J Pharm Sci. 1963;52(12):1145-1149.

22. Korsmeyer RW, Gurny R, Doelker E, Buri P, Peppas N. Mechanisms of potassium chloride release from compressed, hydrophilic, polymeric matrices: effect of entrapped air. J Pharm Sci. 1983;15(1): 1189-1191.

23. Ritger P, Peppas N. A simple equation for description of solute release. II. Fickian and anomalous release from swellable devices. $J$ Control Release. 1987;5:37-42.

24. European Parliament. Directive 2010/63/EU of the European Parliament and of the Council of 22 September 2010 on the protection of animals used for scientific purposes. 2010;L 276/33 D:33-79. Available from: http://ec.europa.eu/environment/chemicals/lab_animals/legislation_en.htm. Accessed January 28, 2015.

25. Kim S-H, Lee SH, Lee HJ. Rapid and sensitive carvedilol assay in human plasma using a high-performance liquid chromatography with mass/mass spectrometer detection employed for a bioequivalence study. Am J Anal Chem. 2010;01(03):135-143.

26. Shewale BD, Sapkal NP, Raut NA, Gaikwad NJ, Fursule RA. Effect of hydroxylpropyl- $\beta$-cyclodextrin on solubility of carvedilol. Indian J Pharm Sci. 2008;70(2):255-257.

27. Patel R, Purohit N. Physico-chemical characterization and in vitro dissolution assessment of clonazepam-cyclodextrins inclusion compounds. AAPS Pharm Sci Tech. 2009;10(4):1301-1312.

28. Pokharkar VB, Mandpe LP, Padamwar MN, Ambike AA, Mahadik KR, Paradkar A. Development, characterization and stabilization of amorphous form of a low Tg drug. Powder Technol. 2006;167(1): $20-25$.

29. Chowdary K, Reddy G. Complexes of nifedipine with beta and hydroxypropyl beta cyclodextrins in the design of nifedipine SR tablets. Indian J Pharm Sci. 2002;64(2):142-146.

30. Jagannathan L, Meenakshi R, Gunasekaran S, Srinivasan S. FT-IR, FT-Raman and UV-vis spectra and quantum chemical investigation of carvedilol. Mol Simul. 2010;36(4):283-290.

31. Jamzad S, Fassihi R. Role of surfactant and $\mathrm{pH}$ on dissolution properties of fenofibrate and glipizide - a technical note. AAPS Pharm Sci Tech. 2006;7(2):E33.

32. Peppas NA. Analysis of Fickian and non-Fickian drug release from polymers. Pharm Acta Helv. 1985;60(4):110-111.

33. Kumar V, de la Luz Reus-Medina M, Yang D. Preparation, characterization, and tabletting properties of a new cellulose-based pharmaceutical aid. Int J Pharm. 2002;235(1-2):129-140.

34. de la Luz Reus Medina M, Kumar V. Evaluation of cellulose II powders as a potential multifunctional excipient in tablet formulations. Int J Pharm. 2006;322(1-2):31-35. 
35. Gohel M, Patel M, Amin A, Agrawal R, Dave R, Bariya N. Formulation design and optimization of mouth dissolve tablets of nimesulide using vacuum drying technique. AAPS Pharm Sci Tech. 2004;5(3):e36.

36. Abed KK, Hussein AA, Ghareeb MM, Abdulrasool AA. Formulation and optimization of orodispersible tablets of diazepam. AAPS Pharm Sci Tech. 2010;11(1):356-361.

37. Bhatt SA, Mandge SA, Prititrivedi. Design, development and optimization of fast dissolving tablet of ondansetron $\mathrm{HCl}$ using mannitol with camphor, a subliming material. Int J Pharm Pharm Sci. 2013;5(3):1-6.

38. Fini A, Bergamante V, Ceschel GC, Ronchi C, de Moraes CA. Fast dispersible/slow releasing ibuprofen tablets. Eur J Pharm Biopharm. 2008;69(1):335-341.
39. Pabari R, Ramtoola Z. Effect of a disintegration mechanism on wetting, water absorption, and disintegration time of orodispersible tablets. J Young Pharm. 2012;4(3):157-163.

40. Kawabata Y, Wada K, Nakatani M, Yamada S, Onoue S. Formulation design for poorly water-soluble drugs based on biopharmaceutics classification system: basic approaches and practical applications. Int J Pharm. 2011;420(1):1-10.

\section{Publish your work in this journal}

Drug Design, Development and Therapy is an international, peerreviewed open-access journal that spans the spectrum of drug design and development through to clinical applications. Clinical outcomes, patient safety, and programs for the development and effective, safe, and sustained use of medicines are a feature of the journal, which has also been accepted for indexing on PubMed Central. The manuscript management system is completely online and includes a very quick and fair peer-review system, which is all easy to use. Visit http://www.dovepress.com/testimonials.php to read real quotes from published authors.

Submit your manuscript here: http://www.dovepress.com/drug-design-development-and-therapy-journal 